Nota Científica

\title{
Germinação e vigor de sementes de pau d'alho sob estresse salino
}

\author{
José Carlos Lopes ${ }^{1}$, Allan Rocha de Freitas ${ }^{1}$, Rômulo André Beltrame ${ }^{1}$, Luan Peroni Venancio ${ }^{1}$, Pedro Ramon Manhone ${ }^{1}$, \\ Fernanda Rodrigues Nunes e Silva ${ }^{1}$
}

'Universidade Federal do Espírito Santo, Centro de Ciências Agrárias, Departamento de Produção Vegetal, Alto Universitário, C. Postal 16, CEP 29500-000, Alegre,ES, Brasil

"Autor correspondente:
jcufes@bol.com.br

Termos para indexação:

Gallesia integrifolia

Desenvolvimento inicial

Salinidade

Antioxidantes exógenos

Index terms:

Initial development

Salinity

Exogenous antioxidants

Histórico do artigo:

Recebido em 22/11/2013

Aprovado em 20/05/2015

Publicado em 30/06/2015

doi: 10.4336/2015.pfb.35.82.631
Resumo - A salinidade dos solos é um dos mais importantes fatores de estresse abiótico, afetando negativamente diversos aspectos da fisiologia e bioquímica das plantas. Este trabalho teve por objetivo avaliar o efeito do pré-condicionamento de sementes de Gallesia integrifolia sob de estresse salino com nitrato de potássio $\left(\mathrm{KNO}_{3}\right)$ e nitropurinato de sódio (SNP). As sementes foram tratadas através do précondicionamento de imersão em soluções com cinco concentrações de $\mathrm{KNO}_{3}(0,0,0,01$, 0,1, 1 e $\left.10 \mathrm{mg} \mathrm{L}^{-1}\right)$ e de $\operatorname{SNP}\left(0,0,01,0,1,1\right.$ e $\left.10 \mathrm{mg} \mathrm{L}^{-1}\right)$ por uma hora. Em seguida, as sementes foram distribuídas em folhas de papel filtro previamente umedecidos com soluções salinas em três potenciais osmóticos $(0,0,-0,6$ e - 1,2 $\mathrm{MPa})$, sendo os rolos de papel mantidos em câmara de germinação do tipo BOD sob temperatura alternada de $20-30{ }^{\circ} \mathrm{C}$ com fotoperíodo de $8 / 16 \mathrm{~h}$ durante 22 dias. Observou-se que o menor potencial osmótico acarretou redução das médias para todas as variáveis avaliadas. O potencial osmótico de $-1,2 \mathrm{MPa}$ influenciou negativamente a germinação e vigor de sementes de pau d'alho. $\mathrm{KNO}_{3}$ e SNP na concentração de $1 \mathrm{mg} \mathrm{L}^{-1}$ proporcionam redução do efeito salino nas sementes.

\section{Germination and seed vigor of Gallesia integrifolia under saline stress}

Abstract - Soil salinity is a major abiotic stress factor, adversely affecting many aspects of plants physiology and biochemistry. This study aimed to evaluate the effect of preconditioning seeds of Gallesia integrifolia with potassium nitrate $\left(\mathrm{KNO}_{3}\right)$ and sodium nitroprussiate (SNP) under saline stress. Seeds were treated through the preconditioning immersion in solutions with five concentrations of $\mathrm{KNO}_{3}(0,0.01,0.1$, 1 and $10 \mathrm{mg} \mathrm{L}-1)$ and of SNP $\left(0,001,0.1,1\right.$ and $\left.10 \mathrm{mg} \mathrm{L}^{-1}\right)$ for one hour. Then, they were distributed in previously moistened filter paper sheets with saline solutions in three osmotic potentials $(0,-0.6$ and $-1.2 \mathrm{MPa})$. The paper rolls were kept in germination chamber type BOD under alternating temperature of $20-30{ }^{\circ} \mathrm{C}$ with photoperiod of $8 / 16 \mathrm{~h}$ for 22 days. It was observed that lower osmotic potential resulted in reduction for all variables average. The osmotic potential of -1.2 MPa influenced negatively the germination and vigor of G. integrifolia. $\mathrm{KNO}_{3}$ and $\mathrm{SNP}$ at concentration of $1 \mathrm{mg} \mathrm{L}^{-1}$ reduces the saline effect in seeds. 
A intensificação do processo de fragmentação das florestas nativas, ocasionada pelo extrativismo desordenado dos recursos naturais, tem gerado a necessidade de descoberta de novas tecnologias que possibilitem a exploração racional e sustentável desses recursos, permitindo a manutenção do equilíbrio dos ecossistemas florestais.

Gallesia integrifolia (Spreng.) Harms, pertencente à família Phytolaccaceae, é uma espécie arbórea nativa do Brasil e apresenta-se distribuída nas Regiões Norte, Nordeste, Centro-oeste, Sudeste e Sul (Marchioretto, 2013). Conhecida popularmente como pau d'alho, é uma espécie não-madeireira, muito utilizada na medicina popular para preparação de chás em tratamentos de doenças, e em sistemas agroflorestais, visto que apresenta bom desenvolvimento em locais de sombreamento moderado e denso, auxilia na manutenção da biodiversidade local e agrega valor aos sistemas agroflorestais já estabelecidos (Santos et al., 2014).

A salinidade dos solos, principalmente pela presença de cloreto de sódio $(\mathrm{NaCl})$, é um dos mais importantes fatores de estresse abiótico, uma vez que afeta diversos aspectos da fisiologia e bioquímica das plantas e compromete seu crescimento (Deuner et al., 2011).

$\mathrm{Na}$ germinação, a água é fator determinante, pois a absorção resulta em reidratação dos tecidos, intensificação do processo respiratório e das demais vias metabólicas que resultarão no desenvolvimento do eixo embrionário (Carvalho \& Nakagawa, 2012).

Em sementes, a redução do vigor é um dos primeiros sintomas de toxidez à salinidade (Lopes \& Macedo, 2008). Em condições de estresse salino, o acúmulo de $\mathrm{NaCl}$ a partir da embebição das sementes ocasiona o rompimento das camadas tegumentares e causa danos ao embrião, podendo levar à morte das sementes (Freitas et al., 2013). Diversos autores relatam que muitas espécies são sensíveis aos efeitos da salinidade ocasionada pelo acúmulo de $\mathrm{NaCl}$ (Lopes \& Dias, 2004; Lopes \& Macedo, 2008; Lopes et al., 2014).

O condicionamento osmótico é uma técnica usada para acelerar e uniformizar a germinação, que consiste na hidratação parcial das sementes sem que ocorra a protrusão da radícula, ocorrendo a síntese de macromoléculas, aumento da atividade de várias enzimas, aumento do poder germinativo, vigor e superação da dormência (Bradford, 1986; Marcos Filho, 2005). A utilização de antioxidantes exógenos pode amenizar o estresse oxidativo. Bewley \& Black (1994) afirmam que a absorção de água, íons e o metabolismo de carboidratos são afetados pela salinidade, culminando com a redução do crescimento e acúmulo de massa seca das plântulas. Desta forma, essa técnica apresenta-se com uma alternativa viável no âmbito da produção de mudas de melhor qualidade em condições de estresse salino.

Nesse sentido, o conhecimento sobre a ecofisiologia da germinação e o crescimento inicial de espécies nativas torna-se fundamental para a produção de mudas. Este trabalho teve por objetivo avaliar o efeito do précondicionamento de sementes de Gallesia integrifolia sob estresse salino com uso de $\mathrm{KNO}_{3}$ e SNP.

O trabalho foi conduzido no Laboratório de Análise de Sementes do Centro de Ciências Agrárias da Universidade Federal do Espírito Santo, Alegre, ES. Foram utilizadas sementes de pau d'alho (Gallesia integrifolia (Spreng.) Harms), coletadas de matrizes localizadas em Seropédica, RJ em setembro de 2012, latitude, $22^{\circ} 45^{\prime} \mathrm{S}$, longitude $43^{\circ} 41^{\prime} \mathrm{W}$ e altitude de 33 $\mathrm{m}$. Após a coleta, as sementes foram retiradas dos frutos e colocadas para secar à sombra durante $72 \mathrm{~h}$.

As sementes foram tratadas separadamente através do pré-condicionamento de imersão em soluções distintas, contendo cinco concentrações de nitrato de potássio $\left(\mathrm{KNO}_{3}\right)\left(0,0,01,0,1,1 \mathrm{e} 10 \mathrm{mg} \mathrm{L}^{-1}\right)$ e de nitropurinato de sódio $(\mathrm{SNP})\left(0,0,01,0,1,1 \mathrm{e} 10 \mathrm{mg} \mathrm{L}^{-1}\right)$, por período de uma hora. Em seguida, foram distribuídas em folhas de papel filtro previamente umedecidas com soluções salinas em três potenciais osmóticos $(0,-0,6$ e - 1,2 MPa) utilizando-se um volume de três vezes a massa do papel seco (Brasil, 2009). Uma vez dispostas no papel filtro, os mesmos foram enrolados e mantidos em câmara de germinação do tipo BOD sob temperatura alternada de 20 - $30{ }^{\circ} \mathrm{C}$ com fotoperíodo de $8 / 16$ h durante 22 dias.

A verificação do número de sementes germinadas foi realizada diariamente até que se tornasse constante. Foram consideradas germinadas aquelas sementes que apresentavam protrusão da raiz primária com dimensão $\geq 2,0 \mathrm{~mm}$. Foi calculado o índice de velocidade de germinação (IVE), de acordo com Maguire (1962). Ao final, foram avaliados o comprimento da raiz (CR) e da parte aérea (CPA), a massa fresca (MF) e a seca (MS), de acordo com Brasil (2009). Para a avaliação da massa seca, as plântulas foram colocadas em sacos de papel tipo Kraft e mantidas em estufa de circulação forçada de ar, com temperatura de $70{ }^{\circ} \mathrm{C}$, até atingirem massa constante, durante $72 \mathrm{~h}$. As massas fresca e seca da parte aérea e do sistema radicular foram determinadas em balança com precisão de $0,0001 \mathrm{~g}$. 
O delineamento utilizado foi inteiramente casualizado (DIC) em dois esquemas fatoriais distintos, onde o primeiro foi 5 × 3 (cinco concentrações de $\mathrm{KNO}_{3} \mathrm{e}$ três potenciais osmóticos) e o segundo $5 \times 3$ (cinco concentrações de SNP e três potenciais osmóticos), ambos com quatro repetições de 25 sementes por tratamento.

Os dados referentes às características avaliadas foram transformados: germinação $\mathrm{Y}=$ [para arco seno $\left.(\mathrm{x} / 100)^{1 / 2}\right]$ e as demais, pela $\left[(\mathrm{x}+0,5)^{1 / 2}\right]$, observadas as pressuposições do teste de normalidade e de homogeneidade de variância. A comparação de médias foi feita utilizando-se análise de regressão.

Ao avaliar a germinação e vigor das sementes (Figuras 1 e 2), observa-se que sob menores potenciais osmóticos, -0,6 e -1,2 $\mathrm{MPa}$, houve redução acentuada em todas as variáveis analisadas, com exceção apenas da massa fresca nos tratamentos com $\mathrm{KNO}_{3}$ e SNP na concentração de $1 \mathrm{mg} \mathrm{L}^{-1}$ (Figuras 1D e 2D), em que foram verificadas as maiores médias.

Nas concentrações dos potenciais osmóticos avaliados, as variáveis germinação e massa fresca de sementes tratadas com $\mathrm{KNO}_{3}$ (Figuras $1 \mathrm{~A}$ e C) e germinação e índice de velocidade de germinação daquelas tratadas com SNP (Figuras 2A e B), não atenderam aos parâmetros de normalidade e significância dos betas.

Tais resultados estão de acordo com aqueles verificados por Lopes \& Dias (2004) em sementes de cenoura, Nunes et al. (2009) para crotalária, Barreto et al. (2010) em sementes de sabiá e Mistura et al. (2011) em sementes de cunhã, em que a germinação e o vigor das sementes apresentaram menores médias em condições de menor potencial osmótico, sugerindo efeito tóxico do $\mathrm{NaCl}$.

Verificou-se que sob potencial osmótico de -0,6 MPa, as sementes tratadas com $\mathrm{KNO}_{3}$ e SNP, nas concentrações de $1 \mathrm{mg} \mathrm{L}^{-1} \mathrm{e} 10 \mathrm{mg} \mathrm{L}^{-1}$, apresentaram as maiores médias nas variáveis avaliadas (Figuras 1 e 2). Todavia, no potencial osmótico de $-0,6 \mathrm{MPa}$, observou-se maiores médias do índice de velocidade de germinação com o uso de $\mathrm{KNO}_{3}$ e $\mathrm{SNP}$, quando comparado às condições sem estresse salino (Figuras 1 e 2).

Nas cinco concentrações de $\mathrm{KNO}_{3}$ e SNP estudadas, somente as variáveis germinação, massa seca (-1,2 MPa) e comprimento da parte aérea das sementes tratadas com $\mathrm{KNO}_{3}$ (Figuras 3A, D e F), e massa fresca (0 MPa) daquelas tratadas com SNP (Figura 4C), atenderam aos parâmetros de normalidade e significância dos betas (Figuras 3 e 4).

Entre as concentrações estudadas, verificou-se que as médias da germinação e índice de velocidade de germinação foram maiores na concentração de $1 \mathrm{mg}$ $\mathrm{L}^{-1}$ de $\mathrm{KNO}_{3}$ e $1 \mathrm{mg} \mathrm{L}^{-1}$ de SNP. A partir da equação da análise de regressão pode-se observar que o ponto máximo é de $51 \%$ de germinação com o uso de $4,36 \mathrm{mg}$ $\mathrm{L}^{-1}$ de $\mathrm{KNO}_{3}$ (Figuras 3 e 4).

Comportamentos similares foram observados ao avaliar as demais variáveis, que também apresentaram maiores médias nos tratamentos com $1 \mathrm{mg} \mathrm{L}^{-1}$ de $\mathrm{KNO}_{3}$ e $1 \mathrm{mg} \mathrm{L}^{-1}$ de SNP em condições de estresse salino (Figuras 3 e 4).

O teste de germinação das sementes em substrato salino tem sido adotado para a determinação da tolerância das plantas ao excesso de sais, sendo complexos os mecanismos pelos quais as plantas toleram a salinidade, envolvendo a síntese molecular, indução enzimática e transporte de membrana (Lemes et al., 2012). Segundo Oliveira et al. (2009) o processo de germinação é afetado quando a difusão de água pelo simplasto das células é interrompida, devido aos potenciais hídricos mais negativos do meio. Sobhanian et al. (2011) afirmam que o estresse salino tem efeito no crescimento e desenvolvimento das plantas, podendo em alguns casos ocasionar a sua morte.

Diversos autores, estudando os efeitos da salinidade no crescimento e desenvolvimento de plantas (Carvalho et al., 2012; Spadeto et al., 2012; Ferreira et al., 2013; Guedes et al., 2013) relataram que o menor potencial osmótico afeta negativamente a germinação e o crescimento inicial das plântulas, semelhante ao encontrado nesse trabalho.

O pré-condicionamento pode reverter alterações prejudiciais nas membranas celulares como a inativação de enzimas e a inibição da síntese proteica, ocasionadas por elevadas concentrações de $\mathrm{Na}^{+}$que deslocam $\mathrm{Ca}^{2+}$ da membrana, afetando a permeabilidade dessas, e este fato é detectado pela saída de $\mathrm{K}^{+}$das células (Taiz \& Zeiger, 2013). Perez \& Jardim (2005), trabalhando com sementes de paineira, observaram que quando pré-condicionadas em $\mathrm{KNO}_{3}$ apresentaram maiores valores de germinação. De forma semelhante, Kopyra \& Gwozdz (2003) verificaram maior germinação das sementes e maior crescimento das raízes de Lupinus luteus em condições de menor potencial osmótico quando as sementes foram pré-condicionadas em SNP. Esses resultados corroboram com os resultados encontrados neste trabalho, e sugerem a utilização do KNO3 e do SNP no pré-condicionamento das sementes de pau d'alho, para reduzir os efeitos de estresse salino. 

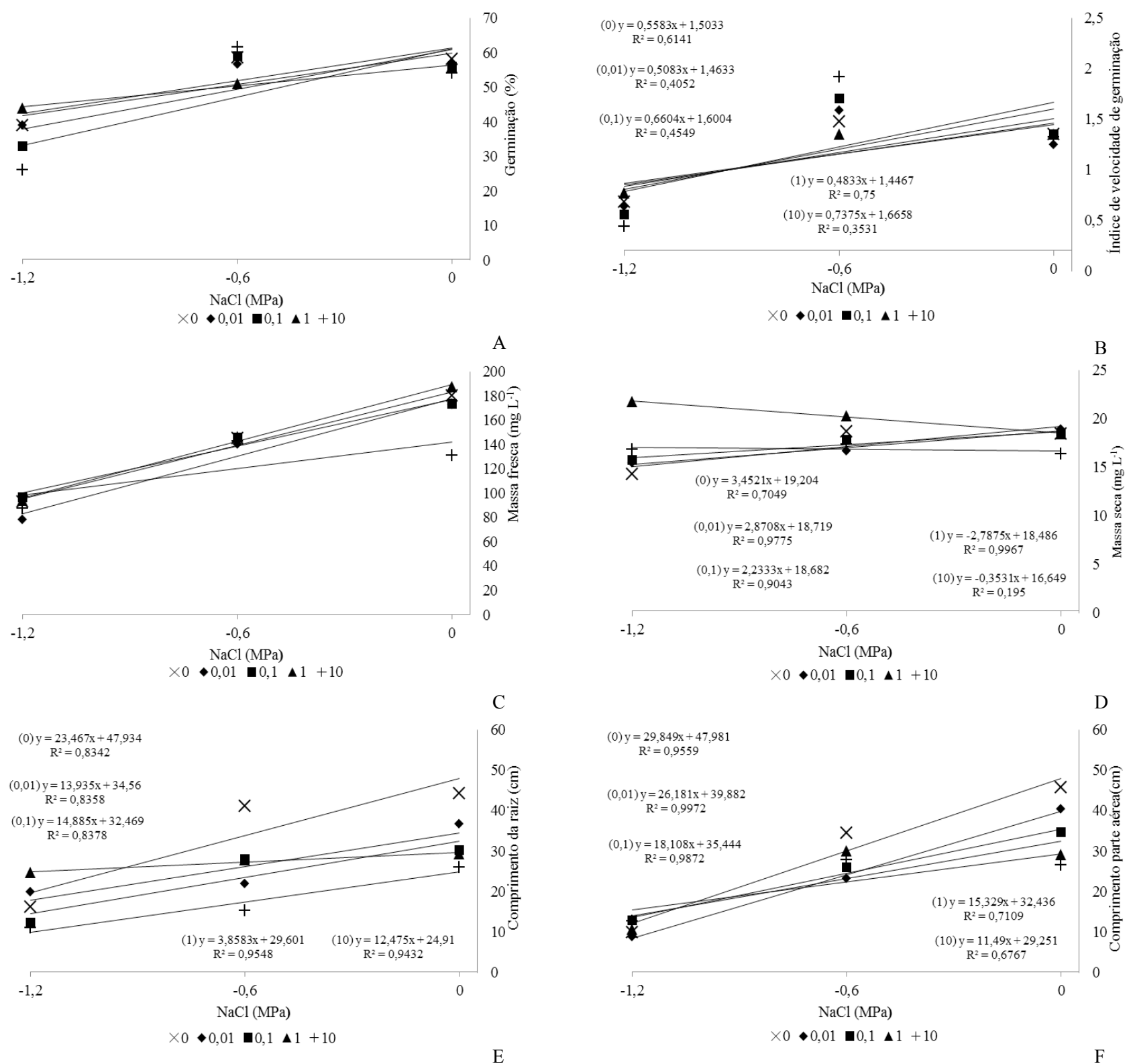

Figura 1. Germinação (A), índice de velocidade de germinação (B), massa fresca e seca (C e D), comprimento da raiz (E) e parte aérea $(\mathrm{F})$ de plântulas de pau d'alho tratadas com $\mathrm{KNO}_{3}\left(\mathrm{mg} \mathrm{L}^{-1}\right)$ em diferentes potenciais osmóticos (MPa). 

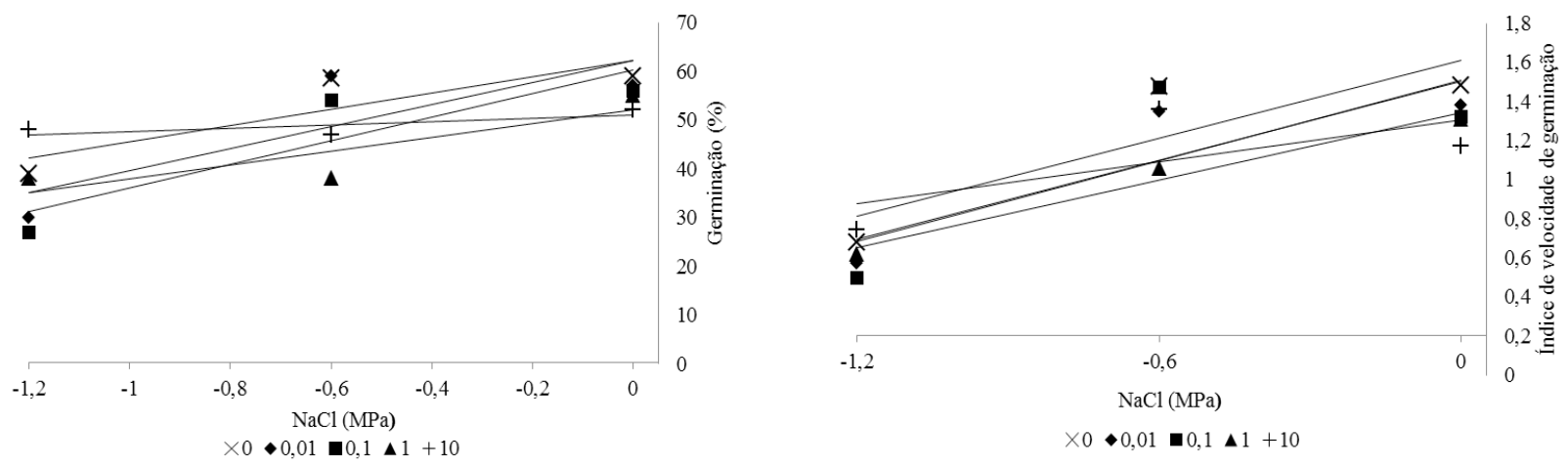

A

B
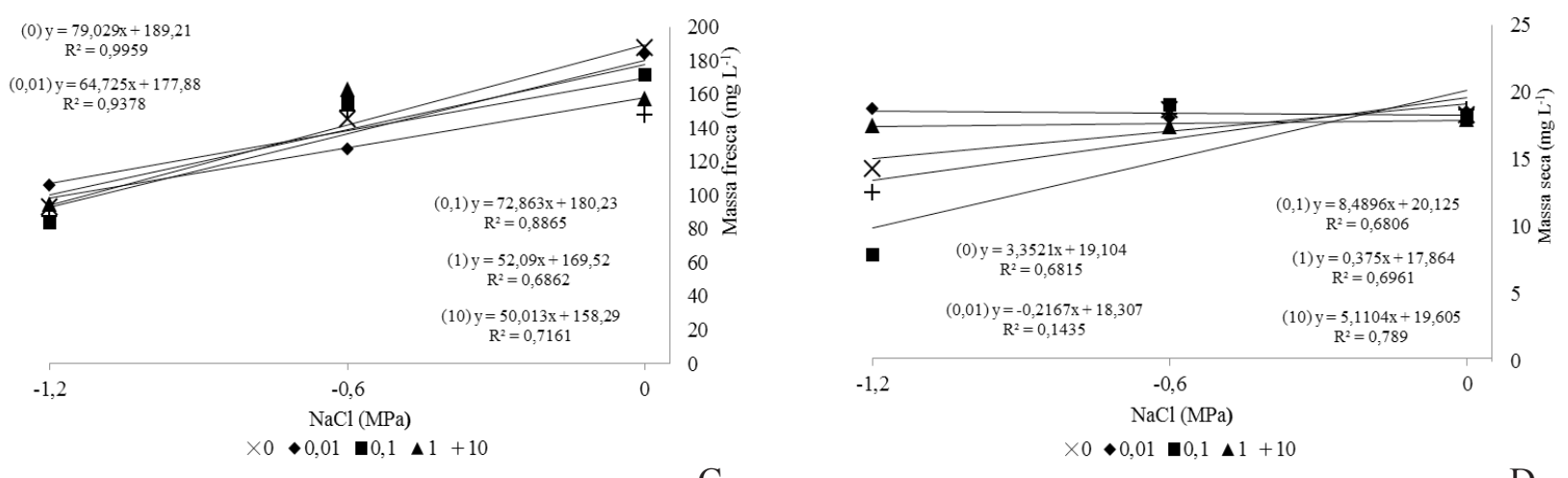

C

$\mathrm{D}$
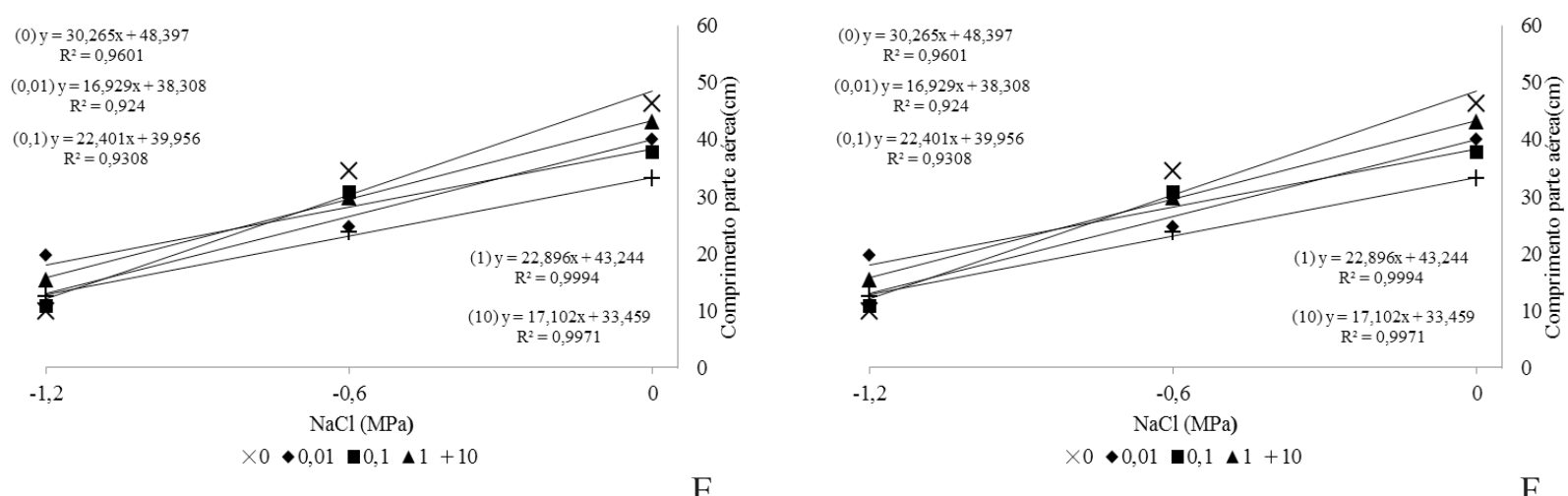

Figura 2. Germinação (A), índice de velocidade de germinação (B), massa fresca e seca (C e D), comprimento da raiz (E) e parte aérea $(\mathrm{F})$ de plântulas de pau d'alho tratadas com SNP (mg L $\left.{ }^{-1}\right)$ em diferentes potenciais osmóticos (MPa). 

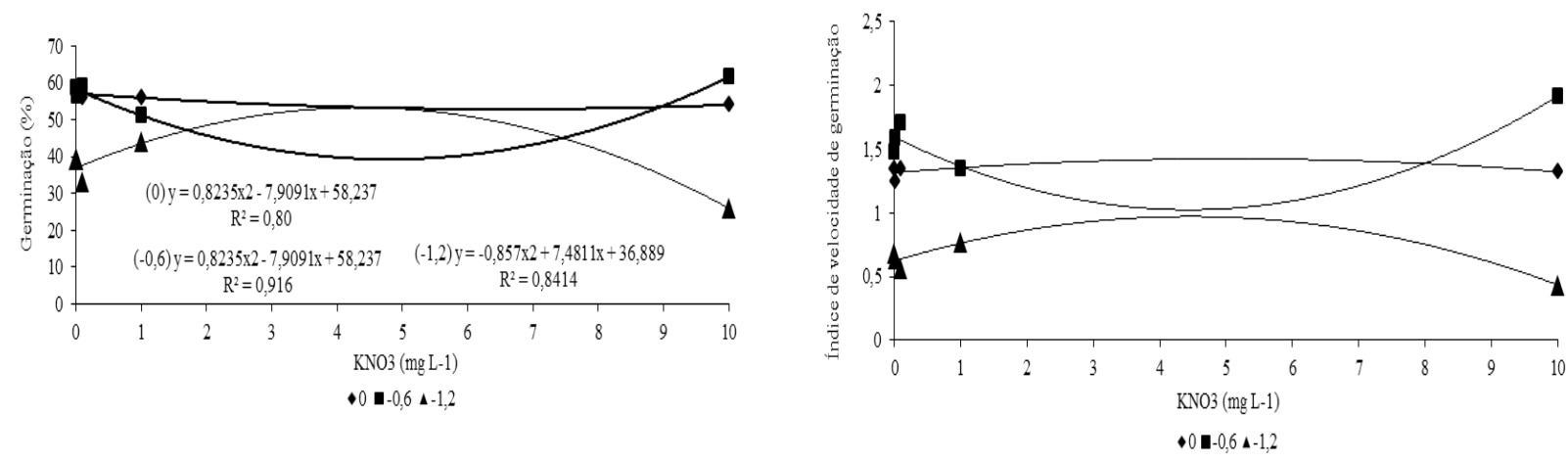

A
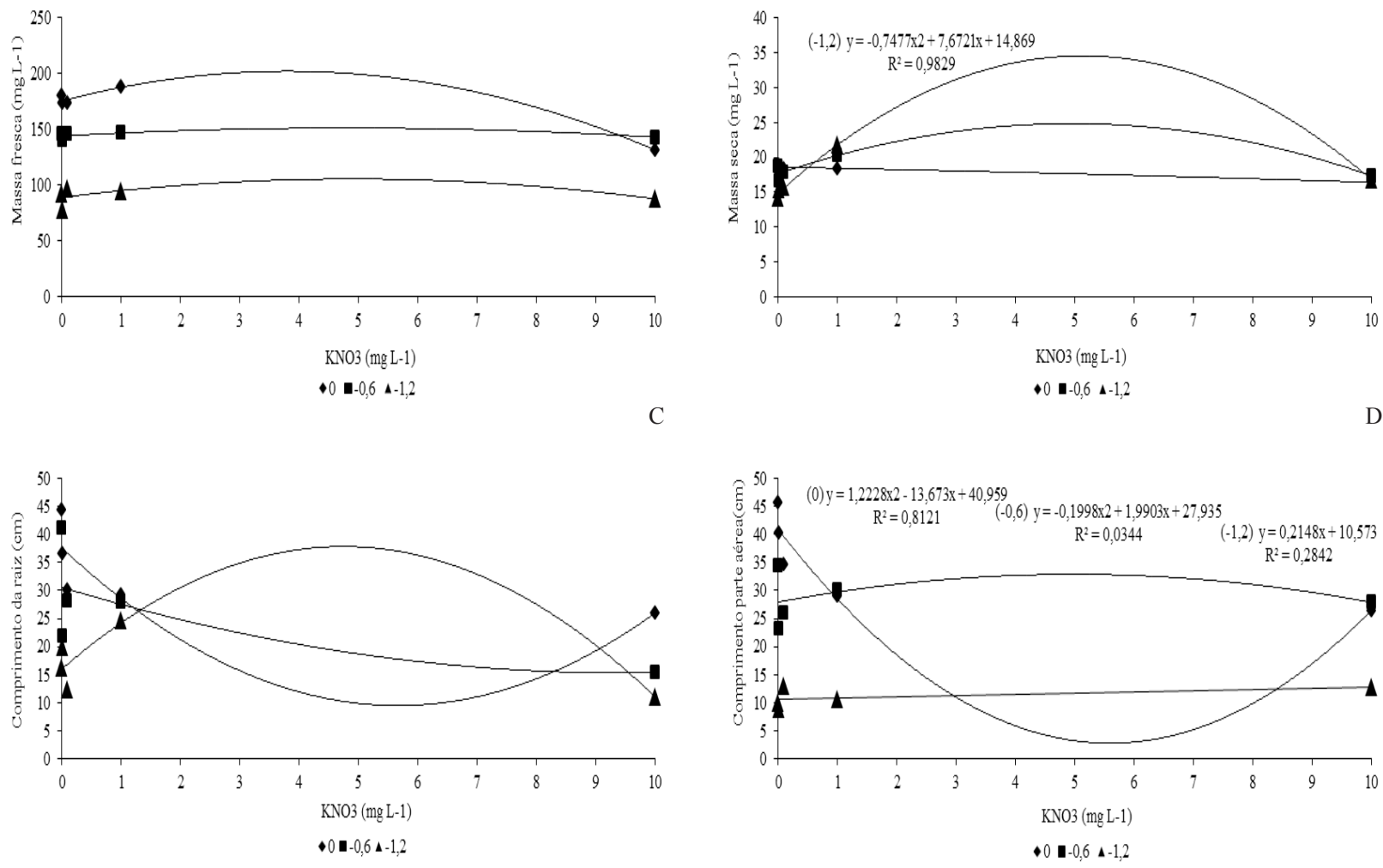

$\mathrm{E}$

F

Figura 3. Germinação (A), índice de velocidade de germinação (B), massa fresca e seca (C e D), comprimento da raiz (E) e parte aérea (F) de plântulas de pau d'alho tratadas com $\mathrm{KNO}_{3}\left(\mathrm{mg} \mathrm{L}^{-1}\right)$ em diferentes potenciais osmóticos (MPa). 


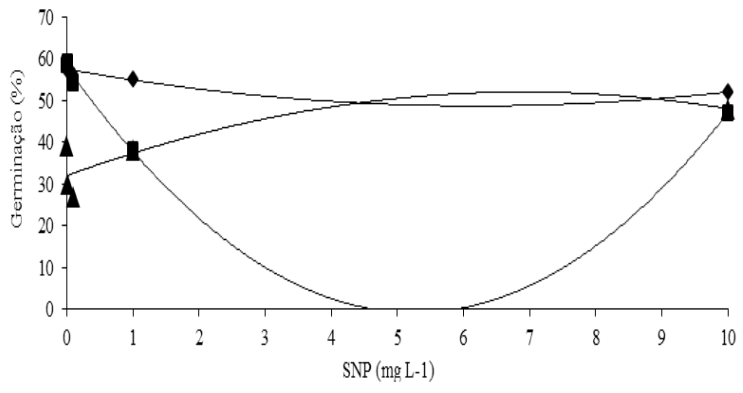

- $0 \mathbf{u}-0,6 \wedge-1,2$

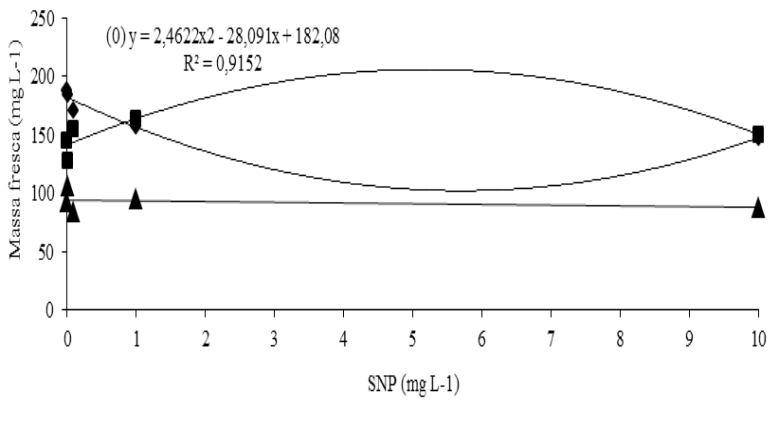

$+0 \square-0,6 \Delta-1,2$

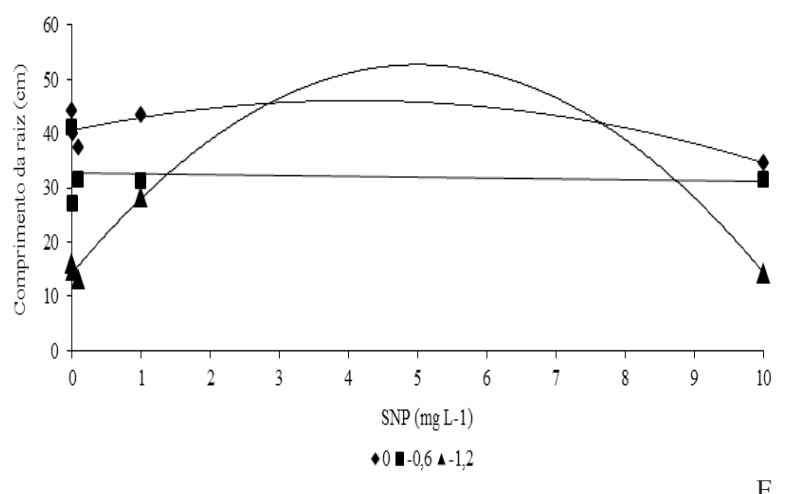

E

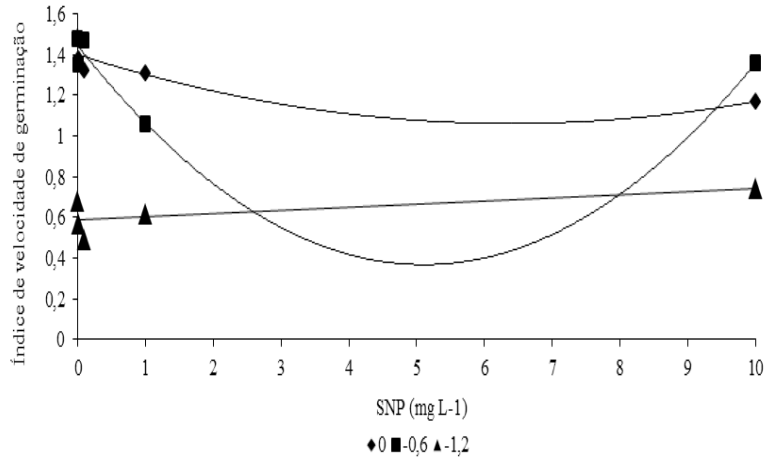

B
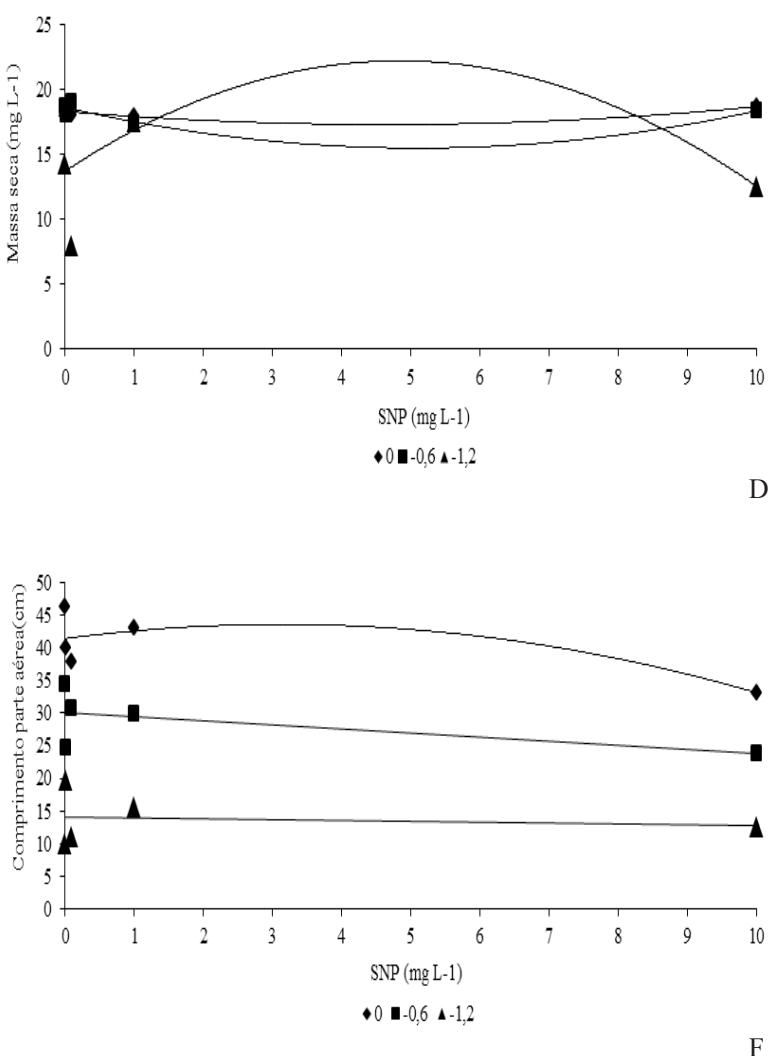

$\mathrm{F}$

Figura 4. Germinação (A), índice de velocidade de germinação (B), massa fresca e seca (C e D), comprimento da raiz (E) e parte aérea (F) de plântulas de pau d'alho tratadas com SNP ( $\left.\mathrm{mg} \mathrm{L}^{-1}\right)$ em diferentes potenciais osmóticos (MPa). 


\section{Conclusão}

O potencial osmótico de $-1,2 \mathrm{MPa}$ influencia negativamente a germinação e o vigor de sementes de pau d'alho.

$\mathrm{O}_{\mathrm{KNO}_{3}}$ e o SNP, na concentração de $1 \mathrm{mg} \mathrm{L}^{-1}$ proporcionam redução do efeito salino na germinação e no vigor das sementes.

\section{Agradecimentos}

Ao CNPq pelas bolsas de PIBIC, de mestrado e de produtividade aos autores, respectivamente.

\section{Referências}

BARRETO, H. B. F.; FREITAS, R. M. O.; OLIVEIRA, L. A. A.; ARAUJO, J. A. M.; COSTA, E. M. Efeito da irrigação com água salina na germinação de sementes de sábia (Mimosa caesalpiniifolia Benth). Revista Verde de Agroecologia e Desenvolvimento Sustentável, Mossoró, RN, v. 5, n. 3, p. 125-130, 2010.

BEWLEY, J. D.; BLACK, M. Seeds: physiology of development and germination. 2nd ed. New York: Plenum Press, 1994. 445 p.

BRADFORD, K. J. Manipulation of seed water relations via osmotic priming to improve germination under stress conditions. Hortscience, Alexandria, v. 21, n. 31, p. 1105-1112, 1986.

BRASIL. Ministério da Agricultura, Pecuária e Abastecimento. Secretaria de Defesa Agropecuária. Regras para análise de sementes. Brasília, DF, 2009. 395 p.

CARVALHO, N. M.; NAKAGAWA, J. Sementes: ciência, tecnologia e produção. 5. ed. Jaboticabal: FUNEP, 2012. 590 p.

CARVALHO, T. C.; SILVA, S. S.; SILVA, R. C.; PANOBIANCO, M. Germinação e desenvolvimento inicial de plântulas de soja convencional e sua derivada transgênica $R R$ em condições de estresse salino. Ciência Rural, Santa Maria, RS, v. 42, n. 8, p. 1366-1371, 2012. DOI: $10.1590 / \mathrm{S} 0103-84782012000800006$

DEUNER, C.; MAIA, M. S.; DEUNER, S.; ALMEIDA, A. S.; MENEGHELLO, G. E Viabilidade e atividade antioxidante de sementes de genótipos de feijão-miúdo submetidos ao estresse salino. Revista Brasileira de Sementes, Londrina, v. 33, n .4, p. 711-720, 2011. DOI: $10.1590 /$ S0101-31222011000400013

FERREIRA, E. G. B. S.; MATOS, V. P.; SENA, L. H. M.; OLIVEIRA, R. G.; SALES, A. G. F. A. Processo germinativo e vigor de sementes de Cedrela odorata L. sob estresse salino. Ciência Florestal, Santa Maria, RS, v. 23, n. 1, p. 99-105, 2013. DOI: 10.5902/198050988444

FREITAS, A. R.; LOPES, J. C.; MATHEUS, M. T.; MENGARDA, L. H. G.; VENANCIO, L. P. CALDEIRA, M. V. W. Superação da dormência de sementes de jatobá. Pesquisa Florestal Brasileira, Colombo, v. 33, n. 73, p. 01-05, 2013. DOI: 10.4336/2013. pfb.33.73.350
GUEDES, R. S.; ALVES, E. U.; VIANA, J. S.; GONÇALVES, E. P.; LIMA, C. R.; SANTOS, S. R. N. Germinação e vigor de sementes de Apeiba tibourbou submetidas ao estresse hídrico e diferentes temperaturas. Ciência Florestal, Santa Maria, RS, v. 23, n. 1, p. 45-53, 2013. DOI: $10.5902 / 198050988438$

KOPYRA, M.; GWOZDZ, E. A. Nitric oxide stimulates seed germination and counteracts the inhibitory effect of heavy metals and salinity on root growth of Lupinus luteus. Plant Physiology and Biochemistry, Paris, v. 41, n. 1, p. 1011-1017, 2003. DOI: 10.1016/j. plaphy.2003.09.003

LEMES, E. Q.; LOPES, J. C.; NOGUEIRA, N. O.; SILVA, L. F.; GOMES JÚNIOR, D.; PEREIRA, D. S. Qualidade fisiológica de Cupania vernalis cambess sob diferentes níveis de salinidade. Revista Trópica: Ciências Agrárias e Biológicas, Chapadinha, v. 6, n. 3, p.144-153, 2012.

LOPES, J. C.; DIAS, M. A. Efeito do estresse salino no vigor e na germinação de sementes e desenvolvimento inicial de plântulas de cenoura. Horticultura Brasileira, Campo Grande, MS, v. 22, n. 2, p. 44,2004

LOPES, J. C.; MACÊDO, C. M. P. Germinação de sementes de couve chinesa sob influência do teor de água, substrato e estresse salino. Revista Brasileira de Sementes, Londrina, v. 30, n. 3, p. 79-85, 2008. DOI: 10.1590/S0101-31222008000300011

LOPES, K. P.; NASCIMENTO, M. G. R.; BARBOSA, R. C. A.; COSTA, C. C. Salinidade na qualidade fisiológica em sementes de Brassicas oleracea L. var. itálica. Semina: Ciências Agrárias, Londrina, v. 35, n. 5, p. 2251-2260. 2014. DOI: 10.5433/1679-0359.2014v35n5p2251

MAGUIRE, J. D. Speed of germination-aid in selection and evaluation for seedlig emergence and vigor. Crop Science, Madison, v. 2 , n. 1 , p. $176-177$, 1962. DOI: $10.2135 /$ cropsci1962.0011183X $000200020033 x$

MARCHIORETTO, M. S. Phytolaccaceae In: REFLORA: lista de espécies da flora do Brasil. Rio de Janeiro: Jardim Botânico do Rio de Janeiro, [2013]. Disponível em:<http://floradobrasil.jbrj.gov.br/ jabot/floradobrasil/FB12578>. Acesso em: 25 Set. 2013.

MARCOS FILHO, J. M. Fisiologia de sementes de plantas cultivadas. Piracicaba: FEALQ, 2005. 495 p.

MISTURA, C.; SANTOS, A. E. O.; ORIKA ONO, E.; RODRIGUES, J. D.; ALMEIDA, M. B.; ARAÚJO, A. J. B. Germinação e desenvolvimento de plântulas de cunhã em função da salinidade. Revista Brasileira Saúde Produção Animal, Salvador, v. 12, n. 2, p. 306-317, 2011.

NUNES, A. S.; LOURENÇÃO, A. L. F.; PEZARICO, C. R.; SCALON, S. P. Q.; MANOEL CARLOS GONÇALVES, M. C. Fontes e níveis de salinidade na germinação de sementes de Crotalaria juncea L. Ciência Agrotecnologia, Lavras, v. 33, n. 3, p. 753-757, 2009. DOI: 10.1590/S1413-70542009000300013

OLIVEIRA, F. R. A.; OLIVEIRA, F. A.; GUIMARÃES, I. P.; MEDEIROS, J. F.; OLIVEIRA, M. K. T.; FREITAS, A. V. L.; MEDEIROS, M. A. Emergência de plântulas de moringa irrigada com água de diferentes níveis de salinidade. Bioscience Journal, Uberlândia, v. 25, n. 5, p. 66-74, 2009. 
PEREZ, S. C. J. G. A.; JARDIM, M. M. Viabilidade e vigor de sementes de paineira após armazenamento, condicionamento e estresses salino e térmico. Pesquisa Agropecuária Brasileira, Brasília, DF, v. 40, n. 6, p. 587-593, 2005. DOI: 10.1590/S0100204X2005000600009

SANTOS, M. S.; FEIJÓ, N. S. A.; SECCO, T. M.; MIELKE, M. S.; GOMES, F. P.; COSTA, L. C. B.; SILVA, D. C. Efeitos do sombreamento na anatomia foliar de Gallesia integrifólia (Spreng) Harms e Schinnus terebinthifolius Raddi. Revista Brasileira de Plantas Medicinais, Botucatu, v. 16, n. 1, p. 89-96, 2014. DOI: 10.1590/S1516-05722014000100013
SOBHANIAN, H.; AGHAEI, K.; KOMATSU, S. B. Changes in the plant proteome resulting from salt stress: toward the creation of salt-tolerant crops. Journal of Proteomics, v. 74, n. 8, p. 1323-1337, 2011. DOI: 10.1016/j.jprot.2011.03.018

SPADETO, C.; LOPES, J. C.; MENGARDA, L. H. G.; MATHEUS, M. T.; BERNARDES, P. M. Estresse salino e hídrico na germinação de sementes de garapa (Apuleia leiocarpa (VOGEL.) J. F. Macbr.). Enciclopédia Biosfera, Goiânia, v. 8, n.14; p. 539-551, 2012.

TAIZ, L.; ZEIGER, E. Fisiologia vegetal. 5. ed. Porto Alegre: Artmed, 2013.918 p. 
